\title{
Key life stages of two predatory ladybird species (Coleoptera: Coccinellidae)
}

\author{
Pavel KINDLMANN ${ }^{1}$ Hironori YASUdA ${ }^{2}$, Satoru SATO $^{2}$ and Katsuhiro SHINYA ${ }^{2}$
}

${ }^{1}$ Faculty of Biological Sciences, University of South Bohemia, Branišovská 31, 37005 České Budějovice, Czech Republic

${ }^{2}$ Department of Agriculture, Yamagata University, Tsuruoka, Yamagata 997, Japan

Key words. Key factor analysis, survival level, larvae, Harmonia axyridis, Coccinella septempunctata, Coccinellidae, ladybirds

\begin{abstract}
Development and survival of larvae of two predatory ladybird species, Harmonia axyridis (Pallas) and Coccinella septempunctata L. on hibiscus (Hibiscus syridis L.) trees was followed daily outdoors during four seasons. Data were analysed and stagespecific mortality in a stage-structured model was estimated using Manly's (1997) method. Subsequently, key factor analysis was used to determine the life stages in which the daily mortality was best correlated with the total mortality during larval life. Consistently with the results from the first two years, the larvae suffered the greatest mortality during the first and fourth instars. The k-values for these two instars were also best correlated with those for the whole larval life, especially in $H$. axyridis.
\end{abstract}

\section{INTRODUCTION}

In nature almost all prey have many types of predators. Predators not only compete with each other, but very frequently kill and eat other predators that use similar resources and are thus potential competitors (Shorrocks et al., 1984). They either cannibalise conspecifics (Fox, 1975; Kawai, 1978; Mills, 1982; Takahashi, 1987, 1989; Agarwala \& Dixon, 1991, 1992, 1993; Dong \& Polis, 1992), or eat individuals of other species, which is called intraguild predation (IGP - see, e.g., Takahashi, 1989; Evans, 1991; Ferran \& Dixon, 1994). The studies on IGP are likely to lead to a reconsideration of many classical topics (Polis et al., 1989; Polis \& Holt, 1992). While there is a reasonable number of theoretical predictions of what the consequences of IGP in model systems should be (Holt \& Polis, 1997; Sih et al., 1998), studies of real IGP interactions, e.g., Dinter (1998) are rare.

Systems consisting of aphids and complexes of predators have attracted attention not only because some aphids are serious pests, but also because native aphid predators have been replaced by introduced ones (Elliott \& Kieckhefer, 1990; Elliott et al., 1996; Brown \& Miller, 1998). Empirical studies on IGP in these systems are laboratory based (Lucas et al., 1998) or done in enclosures in the field (Rosenheim et al., 1993; Ferguson \& Stiling, 1996). The only field studies on the population dynamics in these systems are those of Osawa (1989, 1991, 1992a, 1992b, 1993) and Hironori \& Katsuhiro (1997).

The first step in analysing census data is to determine the numbers of individuals entering each life stage (instar) and the mortality rate in each stage. Although this might seem to be an easy task, there is a problem with field data (density estimates) as each individual may be counted several times. Solutions to this problem have been proposed by many researchers (e.g., Kiritani \& Nakasuji, 1967; Bellows \& Birley, 1981; Bellows et al., 1982; Sawyer \& Haynes, 1984; Manly, 1985, 1993; Schneider \& Ferris, 1986; Manly, 1997).
The next step is to identify the factors responsible for population change, for which key factor analysis is used by some (Sibly \& Smith, 1998; Yamamura, 1999). Only after key factors have been identified and tested statistically, can one determine mechanisms responsible for inter- and intraspecific interactions in these systems.

Here we use Manly's (1997) method to estimate mortality rates of individual instars in a field system consisting of the aphid, Aphis gossypii Glover, feeding on trees of Hibiscus syridis L. and larvae of two predatory ladybird species, Harmonia axyridis (Pallas) and Coccinella septempunctata $\mathrm{L}$. We show that this method satisfactorily fits the empirical data. We then use the estimated mortality rates to identify key factors of the system dynamics.

\section{MATERIAL AND METHODS}

Study site and sampling method

The study site was located on the Yamagata University farm (Tsuruoka, Yamagata pref., 38 $43^{\prime} \mathrm{N}, 139^{\circ} 49^{\prime} \mathrm{E}$ ). It consisted of about 100 trees of $H$. syridis, which is the primary host of the aphid $A$. gossypii. The aphids were preyed upon by larvae of two predatory ladybird species, $H$. axyridis and C. septempunctata. In each of the years $1993-1996$ trees approximately $2 \mathrm{~m}$ in height were selected for study (5 in 1993, 3 in 1994, 10 in 1995 and 12 in 1996). The locations of coccinellid egg batches laid on the leaves of these trees were marked by painting or fixing a small plastic tag with wire to the stalks of the leaves. The numbers of eggs, larvae, pupae, and newly emerged coccinellid adults were counted every day from the middle of May to the middle of July in 1993 to 1996 . The instar of larvae was determined by their size and degree of development by the yellow spots on their abdomens (the reference individuals for determination of the yellow spot development in individual instars were reared in the laboratory).

It is difficult to identify these two coccinellid species in the egg stage because their eggs are similar in size, colour, number in an egg batch, mass and morphology. In 1993 to 1996, the eggs were identified by the larvae that hatched from them. In 1994, a few eggs were removed from each egg mass and placed 
in Petri dishes at $25^{\circ} \mathrm{C}$ and a $14 \mathrm{~L}: 10 \mathrm{D}$ photoperiod in the laboratory, and identified to species when the larvae hatched.

\section{Data analysis}

The most recent study by Manly (1997) is the most adequate for our system, as it is the only one that allows the mortality rates to be constant within, but different between individual instars and simultaneously does not require a priori estimates of instar durations. This method is too complicated to be explained here in any detail - we therefore refer to the original source for description. We approximated the number entering stage 1 by a 4th order polynom and using the program provided by the author (Manly, 1997) we estimated the survival rates for the 4 different instars. Instar durations were assumed to be the same for all animals, and not known in advance. Yearly totals for each of the four years of data were used as inputs.

When the stage specific survival rates, $s$, were fitted, the $\mathrm{k}$-values, $k$, were calculated as $k=-\ln (s)$ and their correlation with the k-values for the total larval life and for the particular year determined. Subsequently, the b-values (slopes of the regression of $k_{i}$ on $K$, where $k_{i}$ is the $k$-value of the $i$-th developmental stage and $\mathrm{K}$ is the $\mathrm{k}$-value for the whole larval stage, were calculated (Podoler \& Rogers, 1975; Yamamura, 1999).

\section{RESULTS}

The stage durations of individual instars (L1-L4) in days were not measured directly - the Manly's method enabled us to estimate them, simultaneously with the corresponding mortality rates, from our empirical data. Total num,bers of individuals on all trees for each of the four years of data were fitted by the Manly's (1997) method. An example of goodness of fit of Manly's model to the empirical data for $H$. axyridis is depicted in Fig. 1 in order to show, how closely the data are fitted, when this method is applied. The estimated instar durations in days of each instar and of both species under study are shown in Tab. 1. The estimated instar specific survival rates and daily survival rates for the two ladybird species studied are depicdted in Fig. 2, in order to visually compare their between-instar differences in different years. Both daily and instar specific survival rates are consistently smallest for the first and fourth instars in both species, although there exists a variability between years.

Table 2 show the k-values for individual larval instars and for the whole larval life and for the total period of observation (1993-96). Not surprisingly, the k-values are largest for the first and fourth instars in both species, as they were calculated from the mortality rates.

Finally, Table 2 shows correlation coefficients, r, between the $\mathrm{k}$-value for the particular instar and that for the whole larval life, and slopes of the regression of $\mathrm{k}_{\mathrm{i}}$ on $\mathrm{K}\left(\mathrm{k}_{\mathrm{i}}\right.$ is the $\mathrm{k}$-value of the $\mathrm{i}$-th developmental stage and $\mathrm{K}$
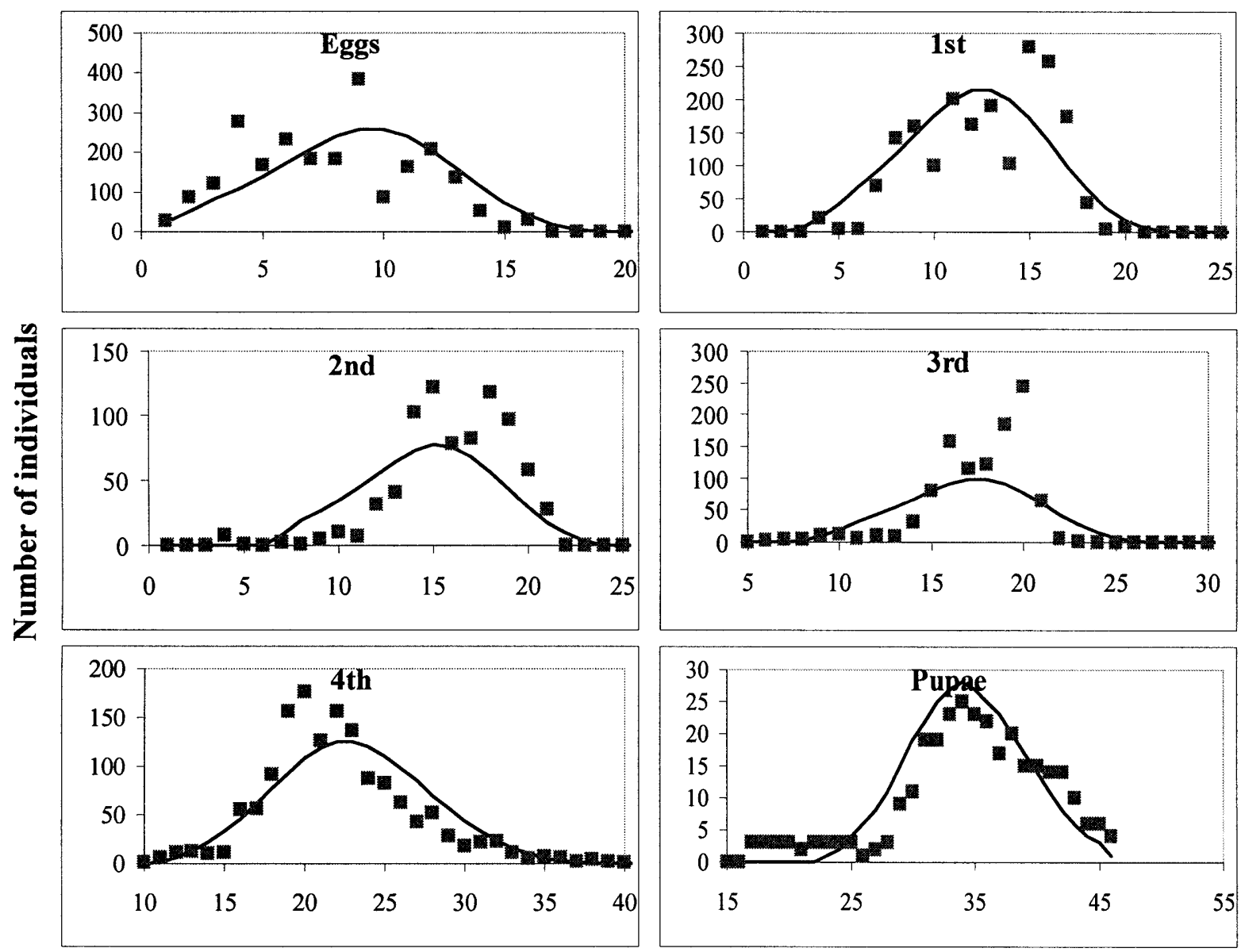

Time (days)

Fig. 1. An example of goodness of fit of Manly's model to the empirical data from 5 trees for H. axyridis from 1993. 
TABLE 1. Estimated stage durations of individual instars (L1-L4) in days.

\begin{tabular}{lcccccc}
\hline Species & \multicolumn{3}{c}{ H. axyridis } & \multicolumn{3}{c}{ C. septempunctata } \\
\hline Year & 1993 & 1994 & 1995 & 1996 & 1993 & 1994 \\
\hline L1 & 1.97 & 8.2 & 1.92 & 2.89 & 3 & 4 \\
L2 & 1.67 & 1.39 & 2.71 & 1.67 & 1.57 & 2.1 \\
L3 & 2.52 & 1.69 & 2.72 & 2.79 & 1.64 & 2.7 \\
L4 & 11.19 & 5.22 & 8.89 & 9.34 & 4.82 & 5.2 \\
\hline
\end{tabular}

is the $\mathrm{k}$-value for the whole larval stage). The $\mathrm{k}$-values for the first and fourth instars are best corraleted with the $\mathrm{k}$-values for the total larval life, although only one of them is statistically significant. The slopes of the regression lines are also largest for the first and fourth instars. The all demonstrates that the first and fourth instars are the best determinants of the total mortality during the larval life (the key instars).

\section{DISCUSSION}

Manly's (1997) method gave a very close fit to our empirical data. One fit is given for H. axyridis in 1993 in Fig. 1. Manly's (1997) method for unknown stage durations failed for C. septempunctata in 1995 and in 1996 therefore the statistical values are not given in Table 1. For these data, Manly's (1997) method with known stage durations was used and the stage durations were estimated as averages of those for 1993 and 1994.

Fig. 2 shows that in both species, the fourth instar was the stage with lowest survival, followed by the first instar, both in terms of the daily and the stage specific mortality. For comparison of levels of mortality among individual life stages of each species, daily survival rates are more suitable than the stage specific ones, as the latter are strongly influenced by stage duration. The ability to estimate daily survival rates is one of the strengths of Manly's (1997) method. Other methods simply assume daily mortality to be the same for all life stages. The survival rates of 4th instars is substantially lower for C. septempunctata than for $H$. axyridis. This is probably because the larvae of $C$. septempunctata are more likely to be eaten by $H$. axyridis than the reverse (Yasuda et al., 2001).

Table 2 reveals that the correlation coefficients between the k-values for individual instars and those for the total larval life are always positive, largest for the 4th instar and in case of $H$. axyridis also for the 1 st instar. Because only 4 years of data were available, only one of the correlation coefficients was significant at the $5 \%$ probability level, but most of them explained at least $2 / 3$ of the total variability. This shows that the key life stage when most of the mortality in the system occurred, was always the 4th instar, especially in $H$. axyridis. The some conclusion can be drawn from the b-values (slopes of the regression of $\mathrm{k}_{\mathrm{i}}$ on $\mathrm{K}$, where $\mathrm{k}_{\mathrm{i}}$ is the $\mathrm{k}$-value of the $\mathrm{i}$-th developmental stage and $\mathrm{K}$ is the $\mathrm{k}$-value for the whole larval stage in Table 2). These values (key-stage analysis Yamamura, 1999) reveal the key life stage even more clearly then the $r$ values. The food source for both ladybird species, the aphids, were scarce when this instar appeared.

Thus at this time there was probably a high degree of cannibalism and IGP occurred (Hironori \& Katsuhiro, 997), which was reflected in the high mortality rates. As the mortality rates for $C$. septempunctata were much
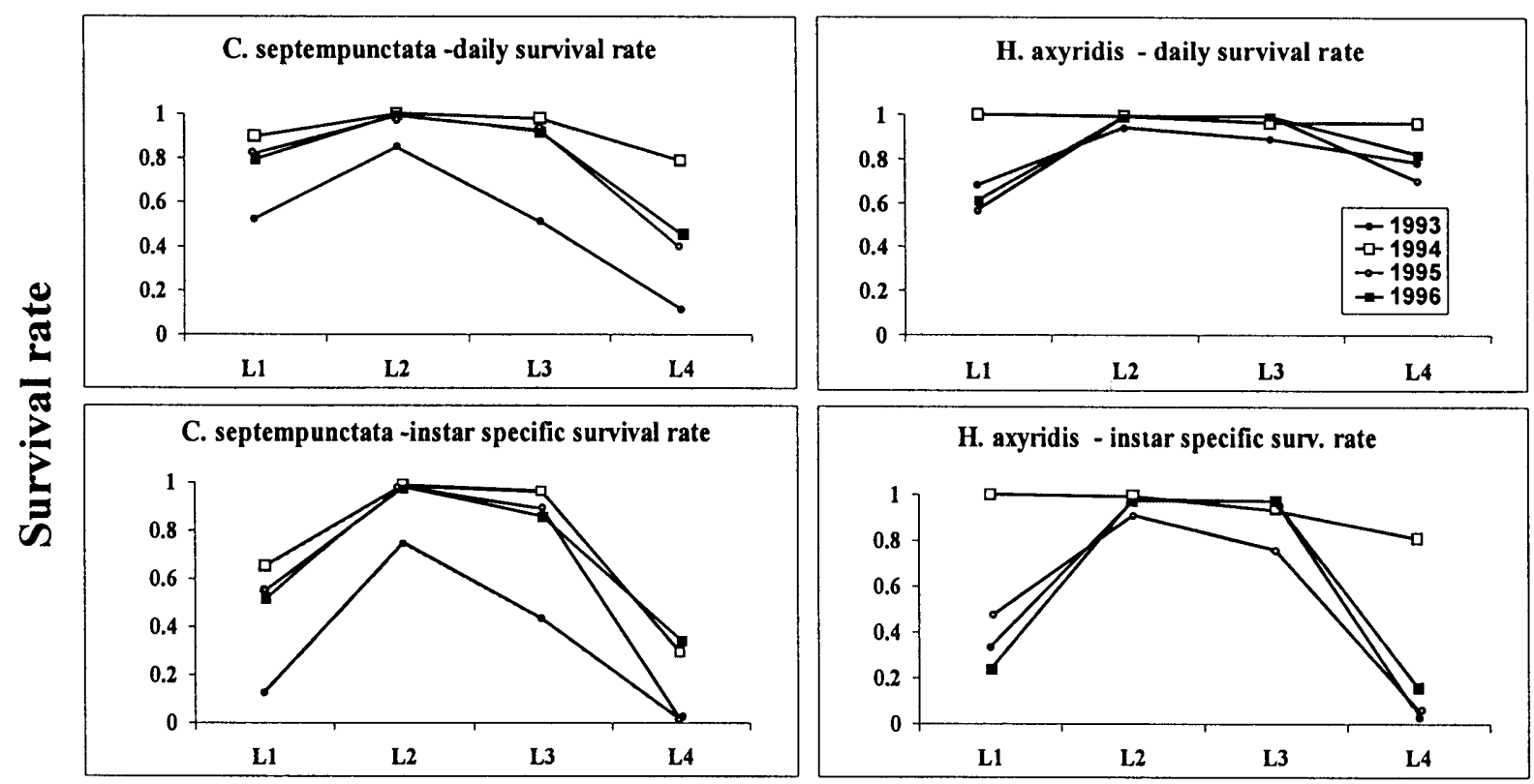

\section{Larval instars}

Fig. 2. Instar specific survival rates and daily survival rates for two ladybird species in different years. L1, L2, L3 and L4 refer to corresponding instars. 
TABLE 2. K-values for individual larval instars and for the whole larval life, for the total period of observation (1993-96), together with the correlation coefficients, $r$, between the $k$-value for the particular instar and that for the whole larval life, and the $b$-values (slopes of the regression of $\mathrm{k}_{\mathrm{i}}$ on $\mathrm{K}$, where $\mathrm{k}_{\mathrm{i}}$ is the $\mathrm{k}$-value of the $\mathrm{i}$-th developmental stage and $\mathrm{K}$ is the $\mathrm{k}$-value for the whole larval stage). Statistically significant correlation coefficient $(\mathrm{p}=0.05)$ is in bold type.

\begin{tabular}{lccccccc}
\hline Species & Stage & 1993 & 1994 & 1995 & 1996 & $\mathrm{r}$ & $\mathrm{b}$ \\
\hline C. septempunctata & L1 & 0.60 & 0.43 & 2.06 & 0.66 & 0.83 & 0.22 \\
& L2 & 0.02 & 0.01 & 0.29 & 0.01 & 0.83 & 0.04 \\
& L3 & 0.12 & 0.04 & 0.84 & 0.15 & 0.82 & 0.11 \\
& L4 & 4.61 & 1.24 & 4.42 & 1.08 & 0.93 & 0.63 \\
H. axyridis & Total & 5.34 & 1.72 & 7.61 & 1.90 & & \\
& L1 & 0.76 & 0.00 & 1.08 & 1.43 & 0.80 & 0.27 \\
& L2 & 0.09 & 0.01 & 0.03 & 0.02 & 0.54 & 0.01 \\
& L3 & 0.27 & 0.07 & 0.03 & 0.03 & 0.19 & 0.01 \\
& L4 & 2.81 & 0.21 & 3.22 & 1.83 & $\mathbf{0 . 9 8}$ & 0.71 \\
\hline
\end{tabular}

higher than those of $H$. axyridis (Fig. 2), one can conclude that $C$. septempunctata was preyed upon by $H$. axyridis. That $C$. septempunctata is vulnerable to attack by $H$. axyridis and is therefore an IGP prey is also supported by our enclosure experiments (Yasuda et al., unpubl.) and by previously published observations (Hironori \& Katsuhiro, 1997).

One could speculate (in agreement with the results on Callosobruchus by Bellows \& Hassell, 1984) that the slightly higher mortality of the 1 st instar of $H$. axyridis is a consequence of the later arrival of this species in aphid colonies (Hironori \& Katsuhiro, 1997). As a result, eggs of $H$. axyridis might have been more vulnerable to predation by the earlier emerging C. septempunctata larvae.

The results presented support those of Hironori \& Katsuhiro (1997), which were based on data from 1993-94 and which were analysed by the suboptimal Kiritani and Nakasuji (1967) method (the Manly's 1997 method was then available) and therefore the results are much less reliable. Here a more advanced method of determination of the number of individuals in individual instars (Manly's 1997 method) was used, which enabled a more accurate estimate. Key factor analysis was used for the first time on these data. This statistical tool was used by Osawa (1993), but he did not distinguish between individual larval instars. Thus his findings that larval mortality is a key factor in $H$. axyridis populations conform with our results, but here we determine the critical instar.

This system supports theoretical predictions concerning ladybird foraging behaviour (Dixon \& Kindlmann, 1995; Dixon et al., 1997; Kindlmann \& Dixon, 1999a, 1999b). Eggs are consistently laid during the "egg window" (period of increase of the aphid population) - see Figs 1, 2 in Hironori \& Katsuhiro (1997). Comparison of the numbers of prey and predator (the same figures) clearly shows that the decline of the aphid population cannot be caused by the predator. It is caused by aphid emigration from the winter host. The critical instars, when the larvae suffer the heaviest mortality, are the 4th and partially also the 1 st. Selection is strongest in these instars, and genotypes that lay eggs in young aphid colonies have a clear advantage. We have shown that late comers (H. axyridis) suffer more 1st instar mortality (Fig. 2), as their eggs are prone to be eaten by $C$. septempunctata larvae, which were laid and hatch earlier (Hironori \& Katsuhiro, 1997). There is no reason for not believing that the same is true intraspecifically. Early comers have an additional advantage during the 4th instar, as they tend to mature earlier and therefore may avoid the period of massive IGP and starvation when the aphid prey become scarce.

In the context of the replacement of native species by introduced ones (Elliott \& Kieckhefer, 1990; Elliott et al., 1996; Brown \& Miller, 1998) that has occurred recently in the USA, our preliminary results suggest that $H$. $a x y$ ridis, when sharing the same resource with $C$. septempunctata, should win in the critical phases towards the end of larval development, when the prey becomes scarce. This is because of ability of 4th instar $H$. axyridis larvae to win when in direct contest with 4th instar $C$. septempunctata larvae (Yasuda et al., 2001).

ACKNOWLEDGEMENTS. We would like to express our thanks to Prof. B. Manly for sending us his program for estimating the parameters in natural stage-structured populations, which made our analyses much easier. The research of the first author was supported by a JSPS fellowship in 1998 and by the grant No. MSM 123100004 of the Czech Ministry of Education.

\section{REFERENCES}

Agarwala B.K. \& Dixon A.F.G. 1991: Cannibalism and interspecific predation in ladybird. In Polgar L., Chambers R.J., Dixon A.F.G. \& Hodek I. (eds): Behaviour and Impact of Aphidophaga. SPB Academic Publishing, The Hague, The Netherlands, pp. 95-102.

Agarwala B.K. \& Dixon A.F.G. 1992: Laboratory study of cannibalism and interspecific predation in ladybirds. Ecol. Entomol. 17: 303-309.

Agarwala B.K. \& Dixon A.F.G. 1993: Kin recognition: egg and larval cannibalism in Adalia bipunctata (Coleoptera: Coccinellidae). Eur. J. Entomol. 90: 45-50.

Bellows T.S. JR. \& BirLeY M.H. 1981: Estimating developmental and mortality rates and stage recruitment from insect stage-frequency data. Res. Pop. Ecol. 23: 232-244.

Bellows T.S., Ortiz M., Owens J.C. \& Huddleston E.W. 1982: A model for analyzing insect stage-frequency data when mortality varies with time. Res. Pop. Ecol. 24: 142-156.

Bellows T.S. \& Hassell M.P. 1984: Models for interspecific competition in laboratory populations of Callosobruchus spp. J. Anim. Ecol. 53: 831-848.

BRowN M.W. \& Miller S.S. 1998: Coccinellidae (Coleoptera) in apple orchards of eastern West Virginia and the impact of invasion by Harmonia axyridis. Entomol. News 109: 143-151. 
DiNTER A. 1998: Intraguild predation between erigonid spiders, lacewing larvae and carabids. J. Appl. Entomol. 122 $163-167$.

Dixon A.F.G. \& KindLMAnN P. 1995: The ladybird fantasy prospects and limits to their use in the biocontrol of aphids. Zuchtungsforschung 1: 395-397.

Dixon A.F.G., Hemptinne J.L. \& Kindlmann P. 1997: Effectiveness of ladybirds as biological control agents: patterns and processes. Entomophaga 42: 71-83.

Dong Q. \& Polis G.A. 1992: The dynamics of cannibalistic populations: a foraging perspective. In Elgar M.A. \& Crespi B.J. (eds): Cannibalism, Ecology and Evolution Among Diverse Taxa. Oxford Science Publications, New York, pp. 13-37.

Elliott N.C. \& KieCKHeFER R.W. 1990: Dynamics of aphidophagous coccinellid assemblages in small grain field in eastern South Dakota. Envir. Entomol. 19 (5): 1320-1329.

Elliott N., Kieckhefer R. \& KaUfFiman W. 1996: Effects of an invading coccinellid on native coccinellids in an agricultural landscape. Oecologia 105: 537-544.

Evans E.W. 1991: Intra versus interspecific interactions of ladybeetles (Coleoptera: Coccinellidae) attacking aphids. Oecologia 87: 401-408.

Ferguson K.I. \& Stiling P. 1996: Non-aditive effects of multiple natural enemies on aphid populations. Oecologia $\mathbf{1 0 8}$ 375-379.

Ferran A. \& Dixon A.F.G. 1994: Foraging behaviour of ladybird larvae (Coleoptera: Coccinellidae). Eur. J. Entomol. 90 : 383-402.

Fox L.R. 1975: Cannibalism in natural populations. Ann. Rev. Evol. Syst. 6: 87-106.

Hironori Y. \& Katsuriro S. 1997: Cannibalism and interspecific predation in two predatory ladybirds in relation to prey abundance in the field. Entomophaga 42: 153-163.

Holt R.D. \& Polis G.A. 1997: A theoretical framework for intraguild predation. Am. Nat. 149: 745-764.

KaWAI A. 1978: Sibling cannibalism in the first instar larvae of Harmonia axyridis Pallas (Coleoptera, Coccinellidae). Kontyu 46: 14-19.

KindLMANN P. \& DixON A.F.G. 1999a: GTRs - determinants of prey abundance in insect predator - prey interactions. Biol. Control 16: 133-138.

Kindlmann P. \& Dixon A.F.G. 1999b: Strategies of aphidophagous predators: lessons for modeling insect predator-prey dynamics. J. Appl. Entomol. 123: 397-399.

KirItani K. \& NaKasurI F. 1967: Estimation of the stagespecific survival rate in the insect population with overlapping stages. Res. Pop. Ecol. 9: 143-152.

LưCas E., Coderre D. \& Brodeur J. 1998: Intraguild predation among aphid predators: characterization and influence of extraguild prey density. Ecology 79 (3): 1084-1092.

MANLY B.F.J. 1985: Further improvements to a method for analysing stage-frequency data. Res. Pop. Ecol. 27: 325-332.

Manly B.F.J. 1993: Note on a method for analyzing stagefrequency data. Res. Pop. Ecol. 35: 215-222.

MANLY B.F.J. 1997: A method for the estimation of parameters for natural stage-structured population. Res. Pop. Ecol. 39 : 101-111.

MrLLs N.J. 1982: Voracity, cannibalism and coccinellid predation. Ann. Appl. Biol. 101: 144-148.
Osawa N. 1989: Sibling and non-sibling cannibalism by larvae of a lady beetle Harmonia axyridis Pallas (Coleoptera: Coccinellidae) in the field. Res. Pop. Ecol. 31: 153-160.

OSAWA N. 1991: Consequences of sibling cannibalism for the fitness of mother and offspring of the ladybirds beetle Harmonia axyridis. In Polgar L., Chambers R.J., Dixon A.F.G. \& Hodek I. (eds): Behaviour and Impact of Aphidophaga. SPB Academic Publishing, The Hague, The Netherlands, pp. 221-225.

OSawa N. 1992a: A life table of the ladybird beetle Harmonia axyridis Pallas (Coleoptera: Coccinellidae) in relation to the aphid abundance. Jap. J. Entomol. 60: 575- 579.

OSAWA N. 1992b: Sibling cannibalism in the ladybird beetle Harmonia axyridis: fitness consequences for mother and offspring. Res. Pop. Ecol. 34: 45-55.

OSAWA N. 1993: Population field studies of the aphidophagous ladybird beetle Harmonia axyridis (Coleoptera: Coccinellidae): life tables and key factor analysis. Res. Pop. Ecol. 35: 335-348.

Podoler H. \& Rogers D. 1975: A new method for the identification of key factors from life-table data. J. Anim. Ecol. 42: 85-114.

Polis G.A., Mrers C.A. \& Holt R. 1989: The evolution and dynamics of intraguild predation between potential competitors. Ann. Rev. Ecol. Syst. 20: 297-330.

Polis G.A. \& HolT R.D. 1992: Intraguild predation: The dynamics of complex trophic interactions. TREE 7(5): 151-154.

Rosenheim J.A., Wilhoit L.R. \& ARMer C.A. 1993: Influence of intraguild predation among generalist insect predators on the suppression of an herbivore population. Oecologia 96: 439-449.

SAWYER A.J. \& HAYNES D.L. 1984: On the nature of errors involved in estimating stage-specific survival rates by Southwood's method for a population with overlapping stages. Res. Pop. Ecol. 26: 331-351.

SChNeIDER S.M. \& Ferris H. 1986: Estimation of stage-specific developmental times and survivorship from stage frequency data. Res. Pop. Ecol. 28: 267-280.

SHORRocks B., Rosewell J. \& Edwards K. 1984: Interspecific competition is not a major organizing force in many insect communities. Nature (London) 26: 310-321.

Sibly R.M. \& Sмiтh R.H. 1998: Identifying key factors using 1 contribution analysis. J. Anim. Ecol. 67: 17-24.

Sin A., Englund G. \& Wooster D. 1998: Emergent impacts of multiple predators on prey. TREE 13: $350-355$.

SMTT R.H. 1973. The analysis of intra-generation change in animal populations. J. Anim. Ecol. 42: 611-622.

TAKAHASH K. 1987: Cannibalism by the larvae of Coccinella septempunctata bruckii Mulsant (Coleoptera: Coccinellidae). Jap. J. Entomol. 31: 201-205.

TAKAHASHI K. 1989: Intra- and inter-specific predations of lady beetles in spring alfalfa fields Jap. J. Entomol. 57: 199-203.

YAMAMURA K. 1999: Key-factor/key-stage analysis for life table data. Ecology 80: 533-537.

YASUdA H., KiKUCHI T. \& KindLMAnN P. 2001: Relation between behaviour, cannibalism and intraguild predation in two predatory ladybirds. J. Insect. Behav. (submitted).

Received January 6, 2000; accepted August 30, 2000 